\title{
The effect of combined mouth wash Gentamycine, Colistin and Vancomycine in prevention of Ventilator Associated Pneumonia in mechanical ventilatory patients admitted to intensive care unit: $A$ randomized Clinical Trial
}

Naser gharebaghi ${ }^{1}, \underline{\text { Mohammad Amin Valizade Hasanloei }}{ }^{2}$, Arash Mosarrezaii Agdam ${ }^{3}$, Sima Mohseni $\operatorname{rad}^{4}$

1. Associate Professor of infectious disease, Urmia University of Medical Sciences, Urmia, Iran. ORCID ID: 0000-00027547-0096

2. Professor of Anesthesiologist and Fellow ship of Intensive Care Medicine, Urmia University of Medical Sciences,Urmia, Iran, (Corresponding Author), Tel: 04433457287; E-mail: aminvalizade@ yahoo.com, ORCID ID: 0000-0003-4377-0884

3. Assistant Professor of Neurologist, Urmia University o Medical Sciences, Urmia, Iran. ORCID ID: 0000-0002-8374-3955

4. General Practitioner, Urmia University of Medical Sciences, Urmia, Iran. ORCID ID: 0000-0002-8139-486X

\begin{abstract}
Background and Aim: Ventilator-acquired pneumonia is common in invasive mechanical ventilatory patients. There are various methods to prevent and reduce the incidence of ventilator-acquired pneumonia, one of which is the use of combined mouthwashes. The purpose of this study was to evaluate the effect of combined mouthwash on the prevention of ventilator-acquired pneumonia.

Materials and Methods: In this clinical-trial study, patients were randomly selected and divided into control and study group. The patients with GCS $=3$ and brain death and mechanical ventilation less than 48 hours were excluded from the study. The control group received $0.2 \%$ chlorhexidine for mouthwash and the study group received gentamicin $2 \%$, colistin $2 \%$ and vancomycin $2 \%$. Mouthwashes were used until the creation of pneumonia symptoms, patient mortality, and endotracheal intubation. Statistical analysis was completed after the study.
\end{abstract}

Results: The incidence of pneumonia was 19 (30.64\%) in the study group and $16(25.8 \%)$ in the control group $(\mathrm{P}=0.23)$. In the study group, $39(62 / 9 \%)$ patients and in the control group 40 patients $(64 / 5 \%)$ were discharged $(\mathrm{P}=49 / 0)$. Cultures endotracheal secretions were reported negatively in 40 patients $(5.64 \%)$ of study group and 45 patients $(58.72 \%)$ in control group $(\mathrm{P}=0.04)$. The isolated bacteria in the study group included 11 cases of Acinetobacter (50\%), four cases of Pseudomonas (18.18\%), two cases of E.coli (9.09\%), two cases of Klebsiella $(9.09 \%)$ and three cases of Gram -positive (16.63\%). Also these bacteria were reported as 11 cases of Acinetobacter (64.7\%), three cases of Klebsiella (17/64\%), two cases of Pseudomonas (11.76\%), one case of E.coli (5.9\%) in control group (P=0.001).

Conclusion: This study showed that a mouthwash with a combination of Gentamicin-Clestin and Vancomycin, compared to chlorhexidine, was not more effective in preventing ventilatorassociated pneumonia in patients undergoing mechanical ventilation.

Keywords: Ventilator-Acquired Pneumonia, Combined Mouthwash, Chlorhexidine, Intensive Care Unit

Received: Dec 5, 2018

Accepted: Oct 8, 2019

\footnotetext{
How to cite the article: Naser gharebaghi, Mohammad Amin Valizade Hasanloei, Arash Mosarrezaii Agdam, Sima Mohseni rad. The effect of combined mouth wash Gentamycine, Colistin and Vancomycine in prevention of Ventilator Associated Pneumonia in mechanical ventilatory patients admitted to intensive care unit: A randomized Clinical Trial. SJKU 2020; 25 (1): 105-116

Copyright (C) 2018 the Author (s). Published by Kurdistan University of Medical Sciences. This is an open access article distributed under the terms of the Creative Commons Attribution-Non Commercial License 4.0 (CCBYNC), where it is permissible to download, share, remix, transform, and buildup the work provided it is properly cited. The work cannot be used commercially without permission from the journal
} 


\title{
تأثير دهانشويه تركيبى جنتامايسين، كلستين و انكومايسين در يِيشيرى از هنومونى اكتسابى از ونتيلاتور در بيماران تحت تهويه مكانيكى بسترى در بخش مر اقبتهاى ويزّي يك كار آزمايى بالينى تصادفى

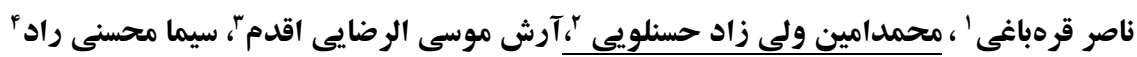

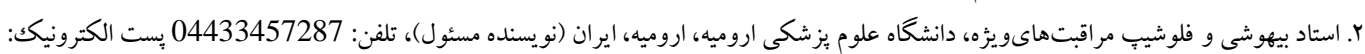

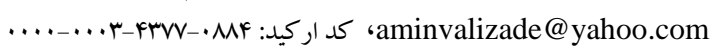

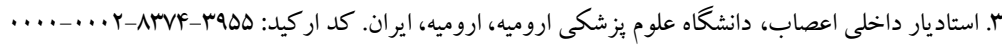

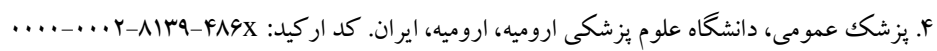

جكيده

زمينه و هدف: بنومونى اكتسابى از ونتيلاتور در بيماران تحت تهويه مكانيكى تهاجمى شايع است، روشهاى مختلف جهت

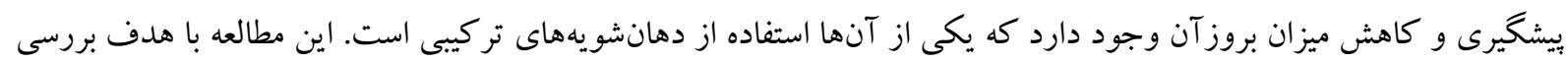
تأثير دهانشويه تركيبى در ييشخيرى از ينومونى اكتسابى از ونتيلاتورانجام شد.

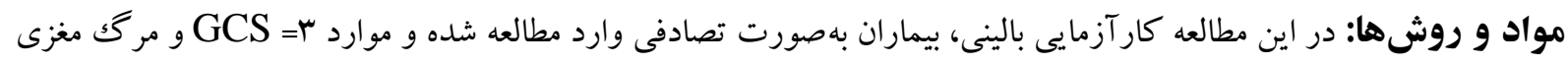

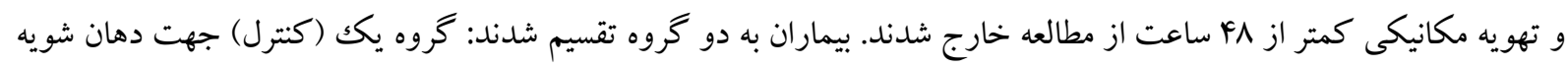

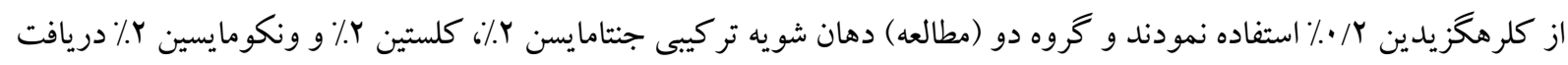

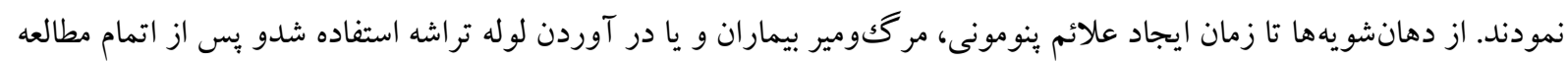

$$
\text { تحت آناليز آمارى قرار گرفت دمانش }
$$

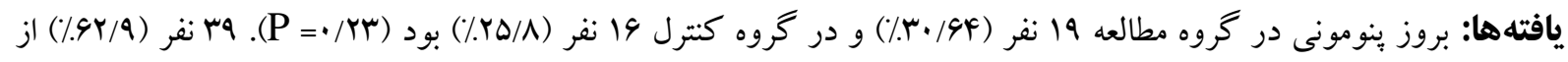

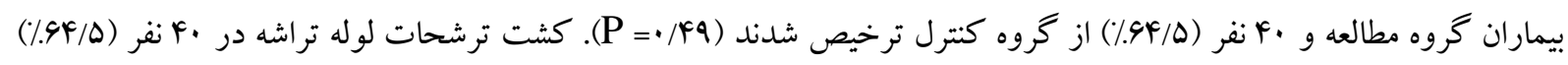

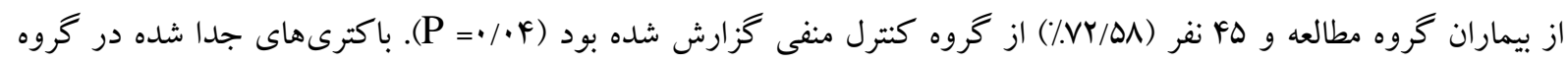

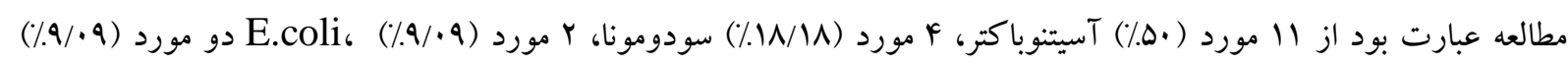

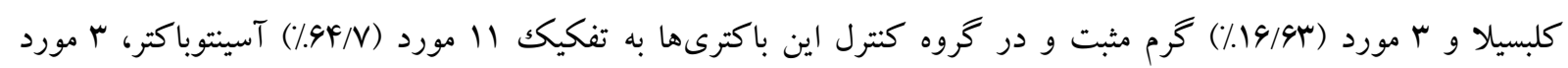

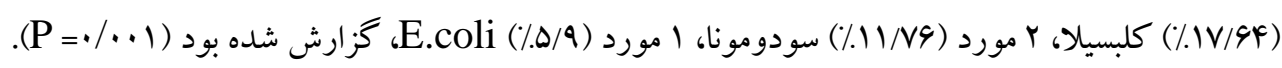

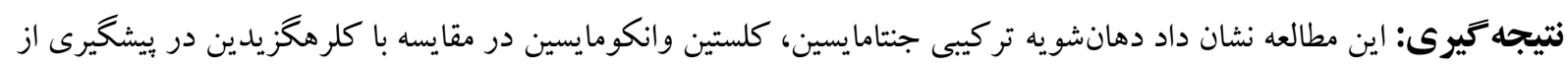

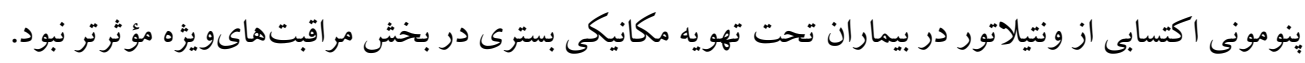

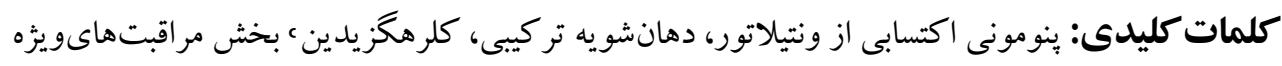


(يوشيده با نقره)، بالا آوردن سر به اندازه D\&F-.r درجه در صورت عدم منع، بهحداقل رساندن استفاده از عوامل مخدر و آرام بخش، حفظ فشار كاف لوله تراشه در اندازه مناسب •r-r.r سانتى متر آب، اندازه گيرى حجم باقى مانده معده جهت جلو گيرى از اتساع بيش از حد معده و بالاخره جداسازى زودتر از ونتيلاتور و تهويه مكانيكى است(ها-

يكى از اقدامات انجام شده جهت بيشخيرى از ابتلاى به ينومونى اكتسابى ناشى از ونتيلاتور، گندزدايى دهانى است

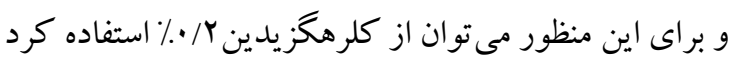
(^). آنتىبيوتيككاى غيرقابل جذب از مخاط دهان روش مؤثرترى از آلودگىزدايى با كلرهكزيدين است كه يك آك رزيم آنتىبيوتيكى شايع عبارت است از مخلوط جنتامايسين

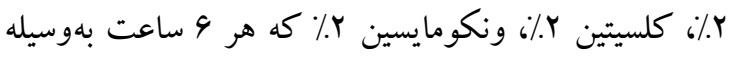
انخشت دستكشدار روى مخاط دهان ماليده مىشود. اين رزيم دارويى باعث از بينبردن گونههاى استافيلوكوك، باسيلهاى هوازى گرم منفى و گونههاى كانديدا در حفره اوروفارنكس مى شود. همجنين اين روش فعاليت اندكى بر روى فلور طبيعى دهان دارد و بههمين خاطر بهعنوان آلود گىزدايى اختصاصى دهانى ناميده مىشود ( •). با توجه به مطالب بيش گفت و بروز نسبتاً بالاى ينومونى اكتسابى از ونتيلاتور در جمعيت بيماران بسترى تحت تهويه مكانيكى تهاجمى و نيز تأثير آن بر بيامدها و افزايش هزينهها

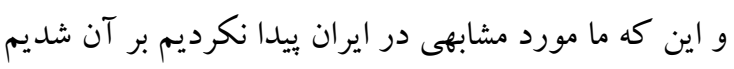
كه مطالعه فوق را در بخش مراقبت هاىويزه بيمارستان امام و آيت ا... طالقانى اروميه انجام و به تأثير دهانشويه تركيبى در بيشخيرى و يا كاهش فراوانى ينومونى اكتسابى از

$$
\text { ونتيلاتور بيردازيم. }
$$

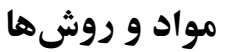

يس از تصويب طرح در شوراى بازنگرى يرويوزال

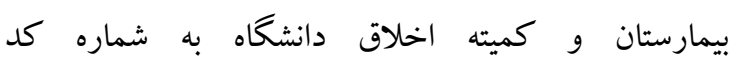

مقدمه

عفونتهاى اكتسابى از بيمارستان جز شايعترين عوارض در

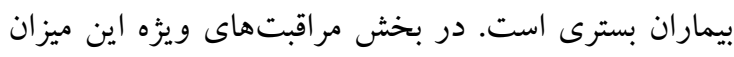

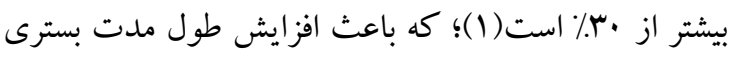

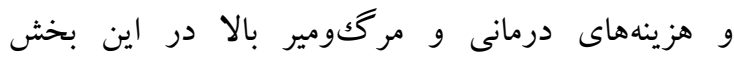

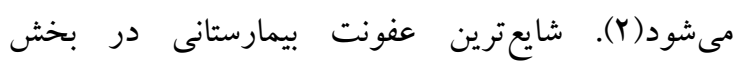

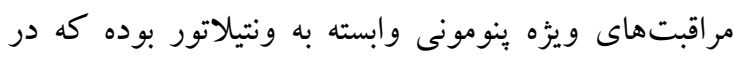

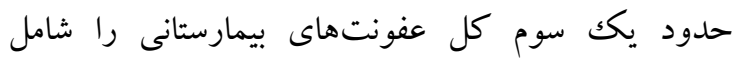

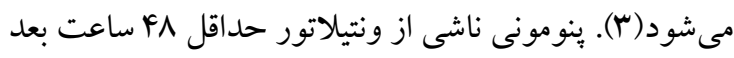

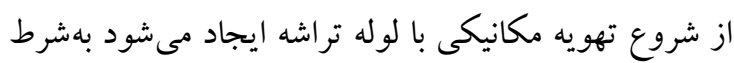
آن كه در زمان لوله كذارى علائم آن وجود نداشته باشد (F).

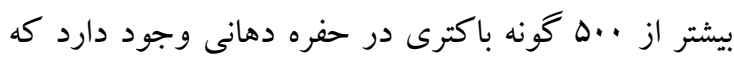
در بيماران بدحال بسترى در بخش مراقبتهاى ويزه به

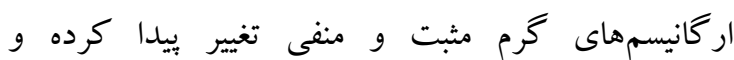

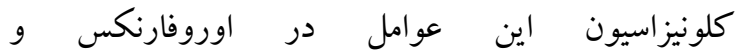
ميكروآسبيراسيون آنها به دستخاه تنفسى تحتانى باعث

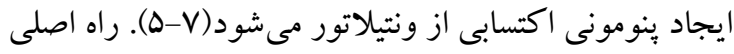

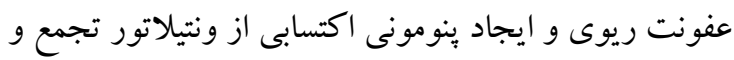

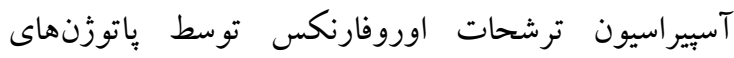
بيمارستانى است(A). تائيد تشخيص پِنومونى ناشى از

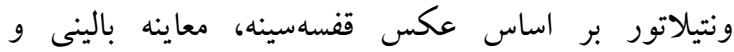
تستهاى ميكروبيولوزى است(9). جنان كه گفته شد يكى از دو مكانيسم دخيل درو ايجاد ينومونى اكتسابى از ونتيلاتور آلودگى باكتريايى حفره دهان

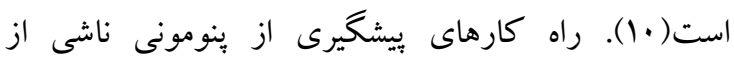

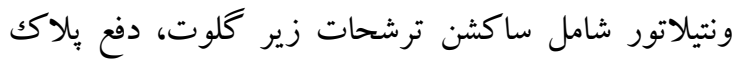

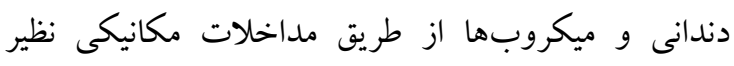
شتشوى دهان، و مسواكك زدن است(Y)؛ و اولين راه برهيز

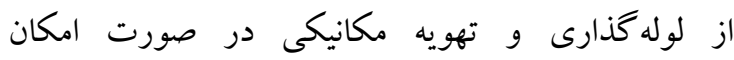
است(11). مداخلات ديخر كه بيشتر جز كارهاى برستارى است شامل شستن دستها، تغيير وضعيت بيماران حداقل هر

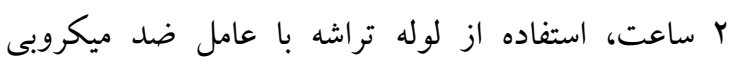


شماره ثبت IRCT20171221037983N5 اين مطالعه تهاجمى به هر دليل و بيمارى زمينهاى قرار داشتند. شرايط خروج از مطالعه شامل بيماران با r= GCS (اغماى عميق و بدون ياسخ به محرك دردناكك) و مركَ مغزى و دريافت

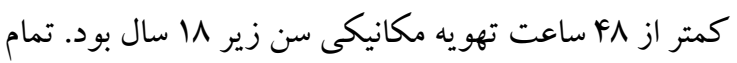
بيماران با لوله تراشه كاف دار با سايز مناسب جهت جنس لهن و

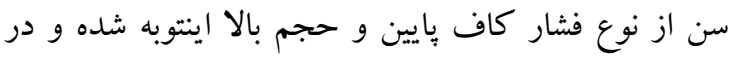

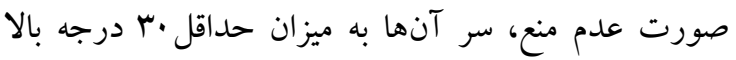

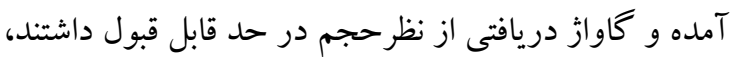

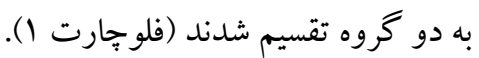

IR.UMSU.REC.1395.205 و اخذ كد IRCT به كار آزمايى بالينى دوسوكور با هدف بررسى تأثير دهانشويه

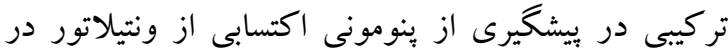

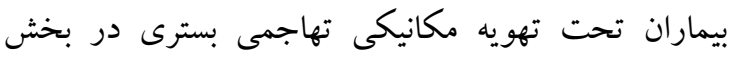

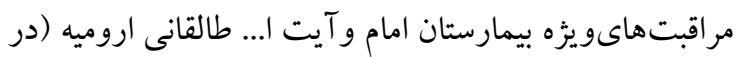

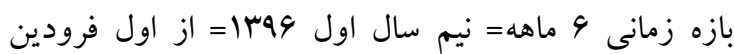
لغايت آخر شهريور) انجام شد. مشخصات بيماران كاملاً محرمانه باقى ماند و محققين به عهدنامه هلسينكى وفادار

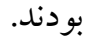
شرايط ورود به مطالعه شامل كليه بيماران بسترى در بخش

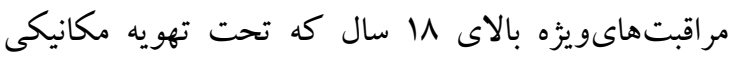

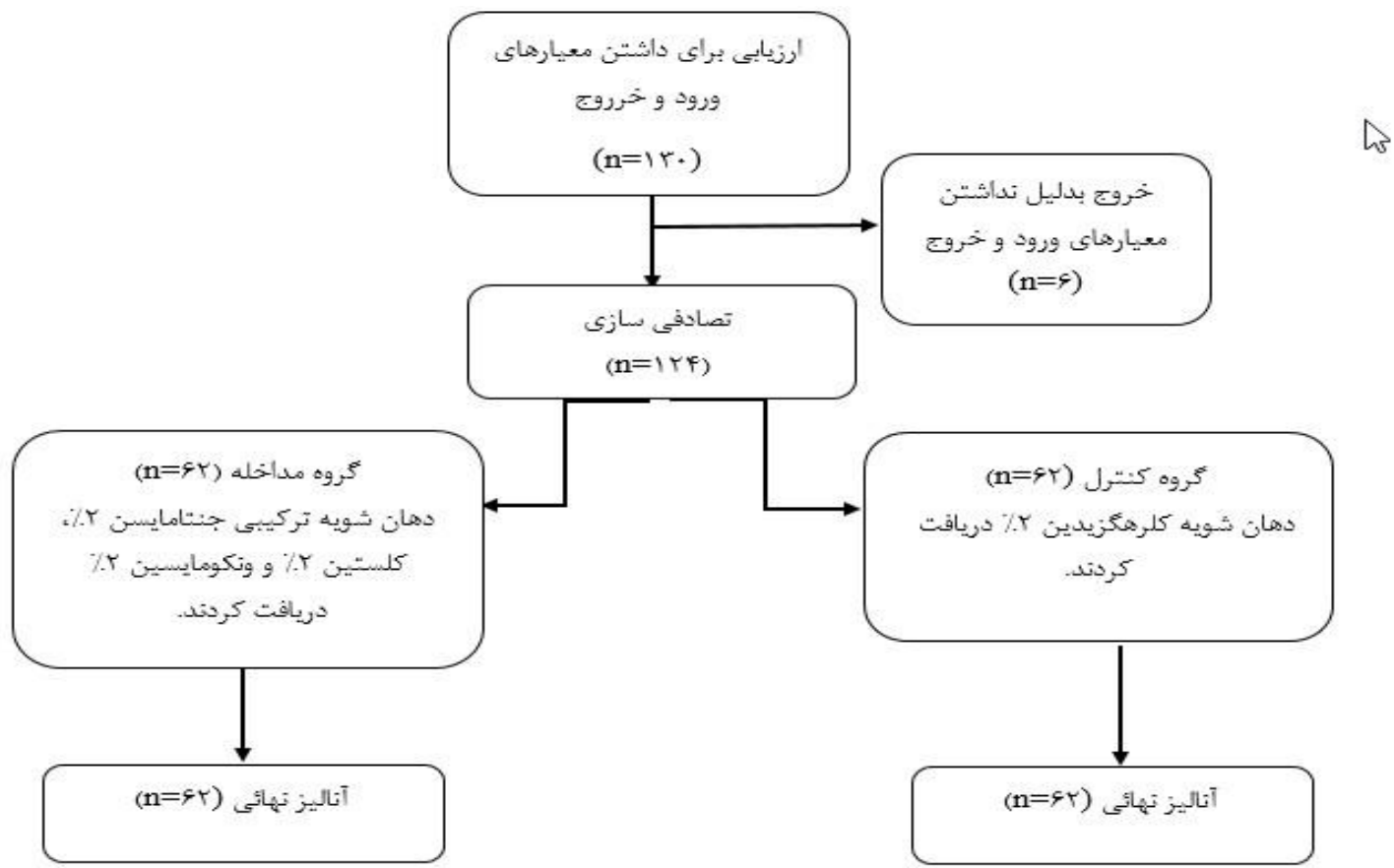

فلوجارت ا. تعداد بيماران مورد مطالعه در Y گروه كنترل و مداخله 
متغيرهاى توصيفى بسته به كيفى و كمىبودن بهصورت درصد فراوانى يا ميانگين با انحراف معيار ارائه شد. براى به مقايسه ميانگين در دو گروه در صورت نرمالبودن دادهها از Chi- استفاده شد. از آزمون Independent T- test square مقايسه فراوانى دو گروه استفاده شد. آناليز دادهها با استفاده از نرم افزار SPSS نسخه سץ انجام و سطح معنىدارى كمتر

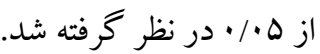

\section{يافتهها}

اطلاعات دمو گر افيكى

در اين مطالعه كارآزمايى بالينى دوسوكور IFF إنفر از بيماران بسترى در بخش مراقبتهاىويزه كه تحت تهويه مكانيكى تهاجمى به هر دليل قرار داشتند وارد مطالعه شدند.

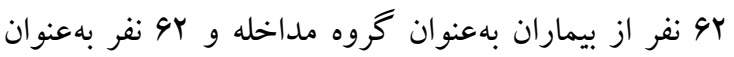
كروه كنترل بررسى شدند.

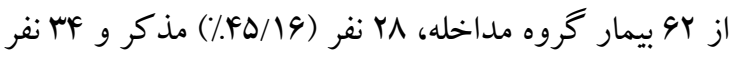

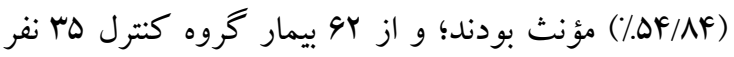

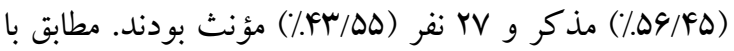
آزمون آمارى Fisher Exact test تفاوت معنىدارى بين جنس بيماران دو گروه مورد مطالعه وجود نداشت (19/•=

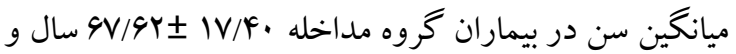

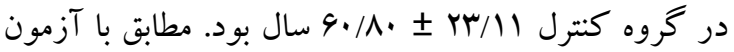
Tارى T-test تفاوت معنىدارى بين ميانگين سن بيماران دو گروه مورد مطالعه وجود نداشت (r/ P

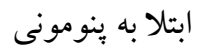

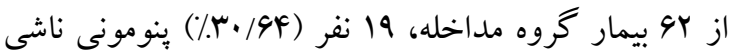

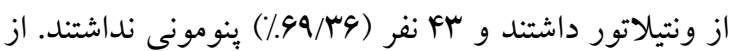

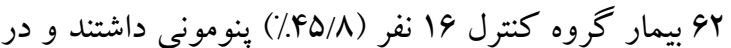

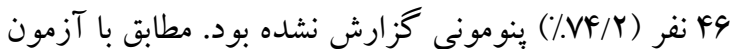

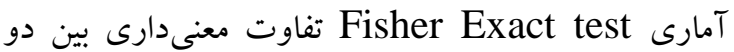

گروه يكك (كنترل) جهت دهانشويه از محلول كلرهكزيدين ז/•٪ جهار بار در روز و بهوسيله سواب آغشته به آن استفاده نمودند و گروه دو (مداخله) از دهان شويه تركيبى جنتامايسن r/\%، كلستين r/\%، ونكومايسين r/ كه

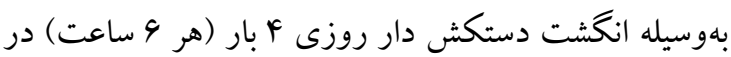
مخاط دهان ماليده مىشد استفاده كردند. از دهان شويهها تا

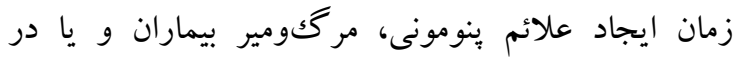

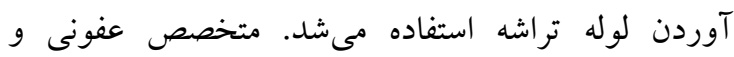
فلوشيب مراقبتهاىويزه بيماران را هر روز ويزيت نموده و

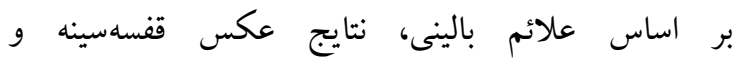

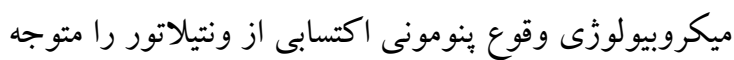
شده و بِ از تشخيص اقدام به درمان آن مئمودند. فشار كاف لوله تراشه بيماران در محدوده فشارى غير آسيبرسان التهان cmH $2 \mathrm{O}$ r.-r.

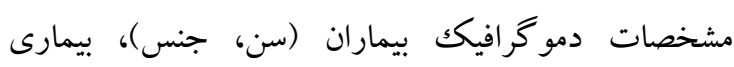
زمينهاى عامل بسترى، طول مدت تهويه مكانيكى، طول

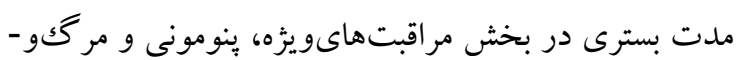
مير و نتايج كشت مثبت ترشحات لوله تراشه در روز هفتم در جّك ليست وارد شده و پِ از اتمام مطالعه تحت آناليز

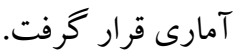
با استفاده از فرمول تعيين حجم نمونه براى مقايسه دو نسبت، بر اساس فراوانى ينومونى در مطالعه رنجبر و همكاران

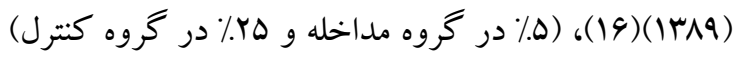

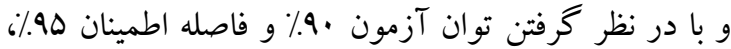
حجم نمونه كو نفر در هر گروه تعيين شد. بيماران بهصورت تصادفى و بر اساس شماره يرونده و بهصورت ساده (شمارههاى فرد در گروه كنترل و شمارههاى زوج در گروه مداخله) وارد مطالعه شدند. مطالعه بهصورت دوسوكور انجام شد. بيمار و محققين از نوع دهانشويه استفاده شده بر ایى بيمار بى بطاطلاع بودند. انجام

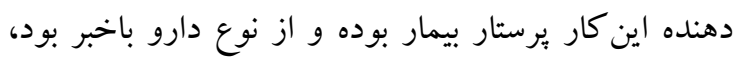

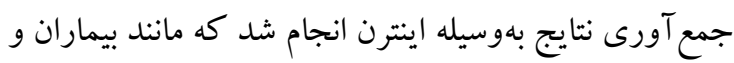
ديخر محققين از نوع دهان شويه بى اطلاع بود. 
از Y

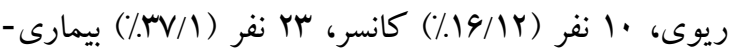
هاى مغزى، F نفر (

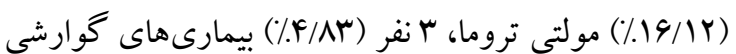
و ه نفر (4/^/^/) بيمارىهاى كليوى داشتند. مطابق با آزمون آمارى Chi-square تفاوت معنىدارى بين بيمارى زمينهاى دو كروه مورد مطالعه وجود دارد (1) (1)
كروه مورد مطالعه و فراوانى ينومونى ناشى از ونتيلاتور وجود نداشت ( بيمارى زمينهاى

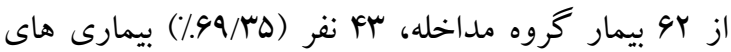
ريوى، 9 نفر (9/9V/\%) مسموميت دارويى، Y نفر (Y/Y/r/\%) كانسر، · انفر (1/1/1\%) بيمارى هاى مغزى و ا نفر (1/9) بيمارى كوارشى داشتند.

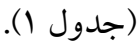

جدول ا. توزيع فراوانى مطلق و نسبى بيمارىهاى زمينه اى در بيماران باو بدون دهانشويه تركيبى

\begin{tabular}{|c|c|c|c|c|c|c|c|c|c|}
\hline \multirow[b]{2}{*}{ جمع كل } & \multicolumn{8}{|c|}{ بيمارى هاى زمينهاى } & \multirow[b]{2}{*}{ كروه } \\
\hline & كليوى & ترولتى & ارتويدى & كوارشى & هاى مغزى - هزى - & كانسر & مسمويت & ريوى & \\
\hline GY & . & . & . & 1 & 1. & r & 9 & $\mathrm{Fr}$ & \\
\hline$(\% 1 \cdots)$ & $(\% \cdot)$ & $(\% \cdot)$ & $(\% \cdot)$ & $(\% 1 / 9)$ & $(\% 19 / 1 Y)$ & $(\% / r / Y r)$ & $(\% / 9 / 9 V)$ & $(\% .99 / r \Delta)$ & مطالعه \\
\hline ar & $\Delta$ & 1. & f & $r$ & rr & 1. & . & v & \\
\hline$(\% 1 \cdots)$ & $(\% / N / \cdot 9)$ & $(\% 19 / 1 Y)$ & $(\% / 9 / 4 \Delta)$ & $(\% / F / A r)$ & $(\% / \mathrm{r} / \mathrm{l})$ & $(\% 19 / 1 Y)$ & $(\% \cdot)$ & $(\% 11 / 49)$ & \\
\hline
\end{tabular}

ميانگين مدت زمان تهويه مكانيكى در گروه مداخله مدت بسترى

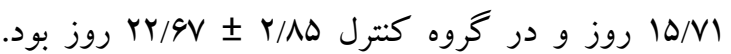
مطابق با آزمون آمارى T-test تفاوت معنىدارى بين

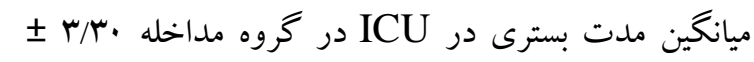
ميانگين مدت تهويه مكانيكى بين دو گروه مورد مطالعه

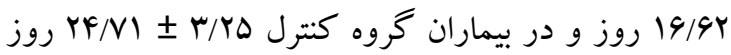

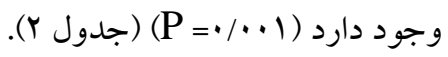
بود. مطابق با آزمون آمارى T-test تفاوت معنىدارى بين ميانگين مدت بسترى در ICU بين دو گروه مورد مطالعه وجود دارد ( ( P

جدول r. مقايسه ميانگين و انحراف معيار طول مدت بسترى در ICU و تهويه مكانيكى در بيماران با و بدون دهانشويه تر كيبى

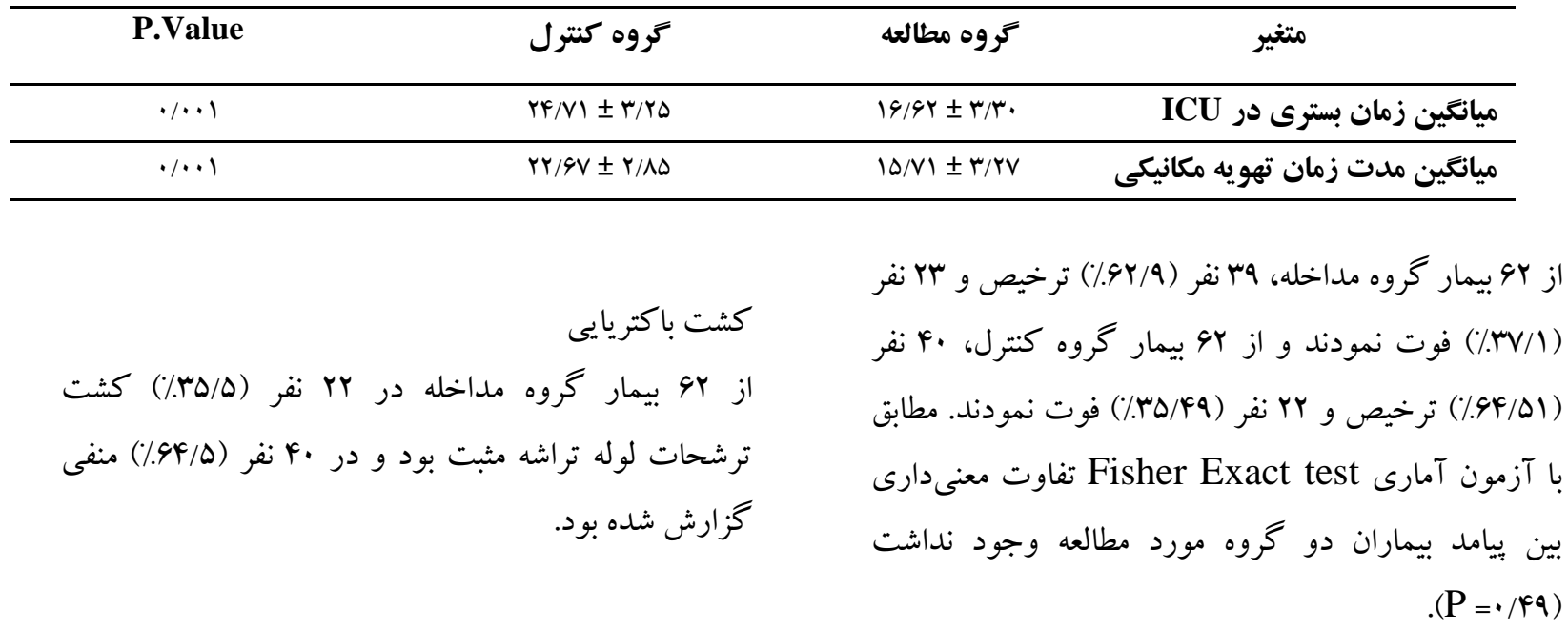




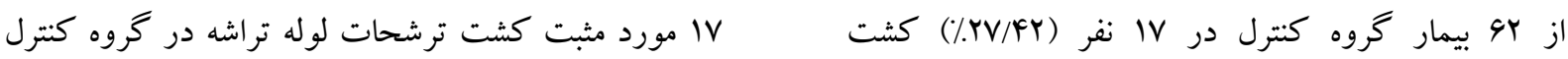

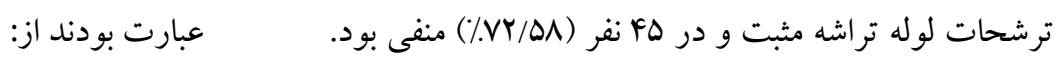

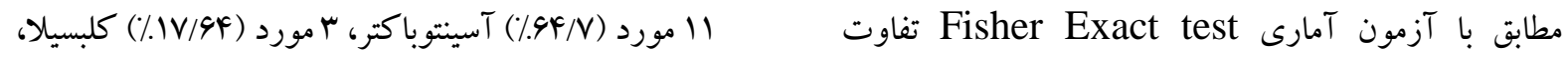

$$
\begin{aligned}
& \text { E.coli (جعنى دارى بين نتايج كشت ترشحات لوله تراشه بين دو }
\end{aligned}
$$

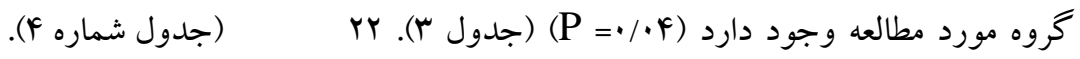

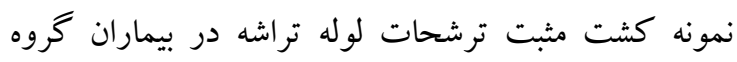

$$
\begin{aligned}
& \text { مداخله عبارت بود از: }
\end{aligned}
$$

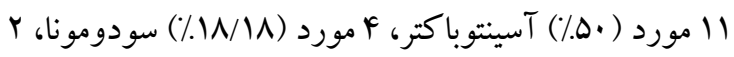

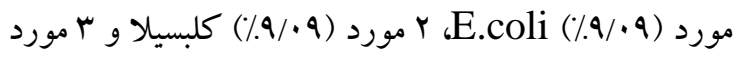

$$
\begin{aligned}
& \text { (1) (1//94) }
\end{aligned}
$$

\begin{tabular}{|c|c|c|c|}
\hline \multirow[t]{2}{*}{ جمع كل } & \multicolumn{2}{|c|}{ كشت ترشحات لوله تراشه } & \\
\hline & منفى & مثبت & \\
\hline$(\% \cdot \cdots) q Y$ & $(/ . g \% / \Delta) F$. & $(\% / r \Delta / \Delta) r r$ & كروه مطالعه \\
\hline$(\% \cdot \cdot \cdot) q r$ & $(\% V Y / \Delta \Lambda) \& \Delta$ & $(\% / Y V / F Y) \mid V$ & كروه كنترل \\
\hline \multirow[t]{2}{*}{$(\% 1 \cdot \cdot) \mid r f$} & $(1.9 \Lambda / \Delta \Delta) \wedge \Delta$ & $(/ / r 1 / F \Delta) r q$ & جمع كل \\
\hline & & Fisher Exact test $=\cdot / \cdot \uparrow$ & P.value \\
\hline
\end{tabular}

\begin{tabular}{|c|c|c|c|c|c|c|c|c|}
\hline \multirow[t]{2}{*}{ جمع كل } & \multicolumn{7}{|c|}{ نوع ميكروب جدا شده از ترشحات لوله تراشه } & \\
\hline & $\frac{y}{y}$ & $\stackrel{9}{(0)}$ & تَ & $\begin{array}{l}13 \\
a \\
2 \\
3 \\
3 \\
3\end{array}$ & $\underset{n}{n}$ & $\begin{array}{l}3 \\
\mathbf{2} \\
\mathbf{\alpha} \\
\dot{3}\end{array}$ & 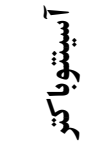 & \\
\hline Yr & . & . & r & $r$ & r & F & 11 & كروه مطالعه \\
\hline$(\% 1 \ldots)$ & $(\% \cdot)$ & $(\% \cdot)$ & $(/ / 9 / \cdot 9)$ & $(\% \mid r / G 4)$ & $(\% / 9 / \cdot 9)$ & $(\% 1 / / \Lambda)$ & $(\% \Delta \cdot)$ & \\
\hline IV & . & . & 1 & . & $r$ & r & 11 & كروه كنترل \\
\hline$(\% 1 \ldots)$ & $(\% \cdot)$ & $(\% \cdot)$ & $(\% / . / 9)$ & $(\% \cdot)$ & $(\% I V / G 4)$ & $(\% 11 / \vee 9)$ & $(\% .94 / \mathrm{V})$ & \\
\hline
\end{tabular}


در مطالعه سيدالشهدايى و همكاران (اqج|) كه با هدف تأثير دهانشويه كلرهخزيدين بر ابتلا به ينومونى ناشى از دستخاه تهويه مكانيكى انجام شد. نتايج نشان داد كه ميزان

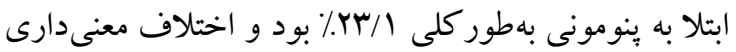

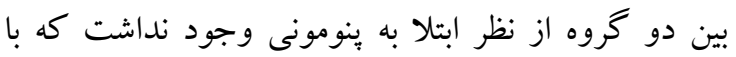

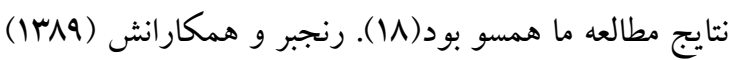

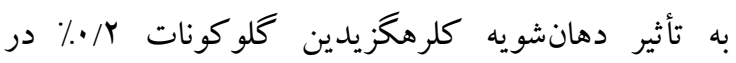

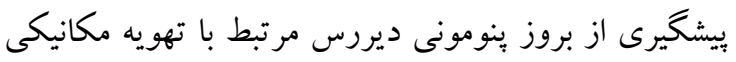

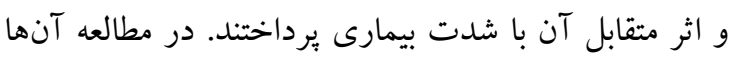

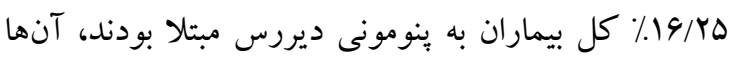

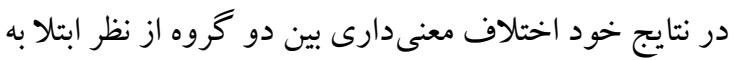
ينومونى را نشان دادند كه با نتايج مطالعه ما و مطالعه

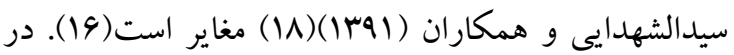
مطالعه رنجبر و همكاران (9/1) بين ميانگين طول مدات بسترى در بخش مراقبتهاىويزه و تهويه مكانيكى اختلاف معنى دار آمارى وجود داشت كه با مطالعه ما همسو بود؛ ولى بلى با مطالعه سيدالشهدايى و همكاران (|جس|)(N|) مغايرت داشت(19). تفاوت اصلى مطالعه ما با دو مطالعه فوق مقايسه تأثير محلول كلر هگزيدين با دهانشويه تركيبى r آنتى بيوتيك جنتامايسين، كلستين وانكومايسين با غلظت بَ بود. يافتهاى مطالعه ما نشان داد تفاوت معنىدارى بين بيامد بيمارانى كه از دهانشويه تركيبى استفاده شده است در مقايسه با بيماران گروه كنترل وجود ندارد. بهطورى كه در بيمارانى كه از دهانشويه تركيبى استفاده شده بود بץ نفر

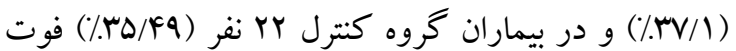

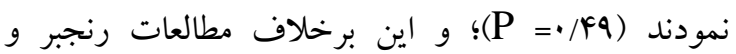

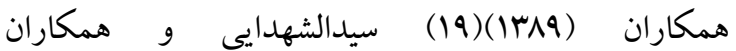

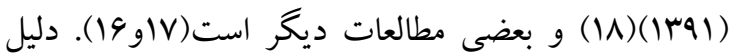
اين تفاوت را بايستى در جمعيت بيماران بسترى و شدت

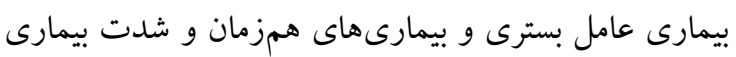

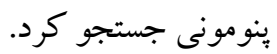
در مطالعه انجام شده توسط Li Li و همكاران (rان. (r) نتيجه گيرى نمودند كه گندزدايى دهانى بروز بنومونى ناشى تُونى
تأمين بهداشت دهان و مراقبت از آن، يكى از وظايف اصلى مراقبين بهداشتى و از جنبههاى اساسى مراقبت برستارى در بخش مراقبتهایويزه است كه نه تنها در ايجاد احساس

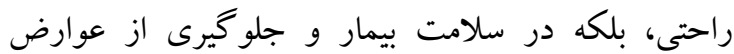

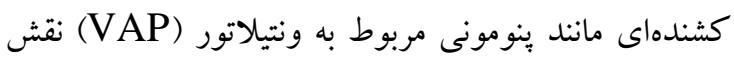

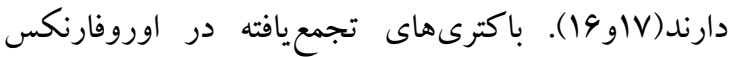
عامل خطرى براى پينومونى مرتبط با ونيتلاتور هستند؛

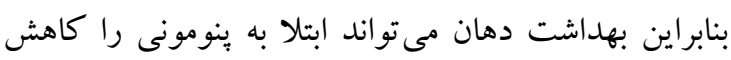

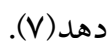
مطالعه حاضر با هدف تأثير دهانشويه تر كيبى در مقايسه با.

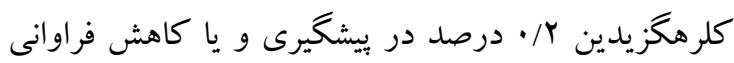

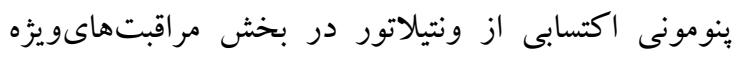
بيمارستان امام و آيت ا... طالقانى اروميه انجام شده است. در اين مطالعه تفاوت معنىدارى از نظر مشخصات

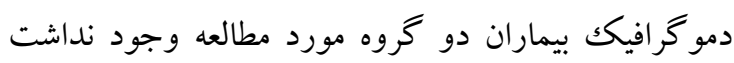

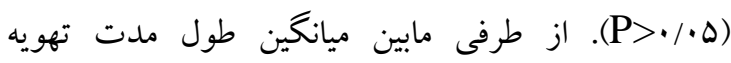
مكانيكى و بسترى در بخش مراقبتهایىويزه تفاوت مات ماتين

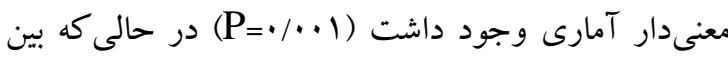

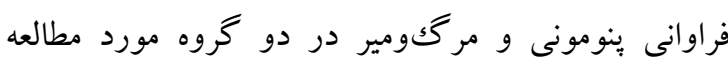

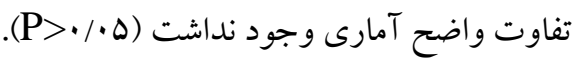
مطالعات متعدد جهت بررسى تأثير استفاده از دهانشويه درو

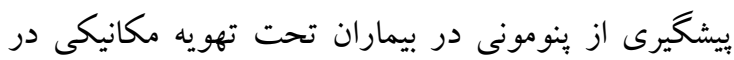
قالب مطالعات كارآزمايى بالينى و مشاهدهاى و مرور

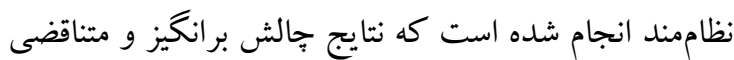
داشته است. بيشتر مطالعات به تأثير محلول دهان شويه

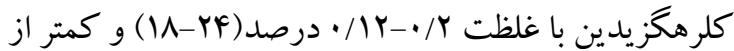
آن محلول نرمال سالين و بتادين(YD) و محلولهاى كمتر

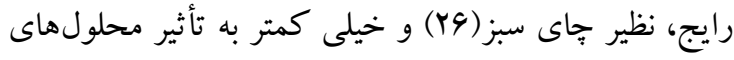

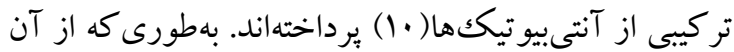
بين سه جهار مطالعه نسبتاً معتبر در داخل كشور در حيطه

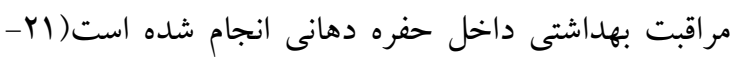


بوده V مطالعه نشان دادهاند كه كلر هكزيدين مؤثر بوده

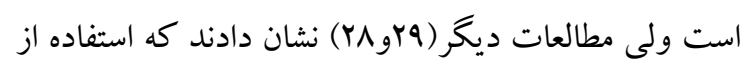

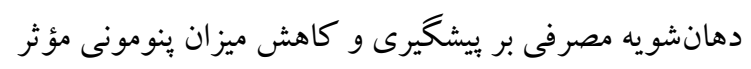

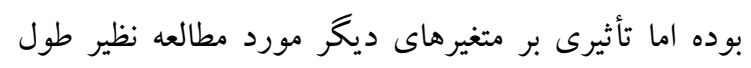
مدت تهويه مكانيكى و بسترى در بخش مر اقبت هاىويزه و

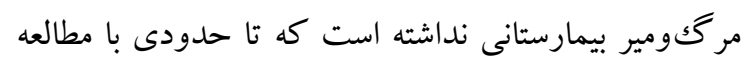
حاضر همسو است. در مطالعه ما تفاوت معنىدارى از نظر كشت ترشحات لوله تراشه بين دو گروه مورد مطالعه وجود داشت بهطورى كه در بيمارانى كه از كلرهگزيدين استفاده نمودند

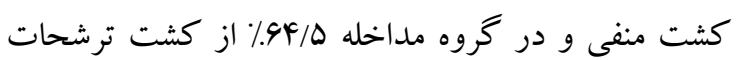

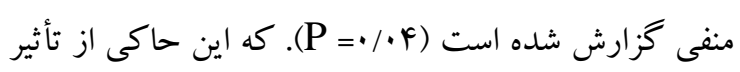
كلرهخزيدين برروى ترشحات لوله تراشه در بيماران بسترى در بخش مراقبت هاىويزه است و اكر در اين مطالعه دهان-

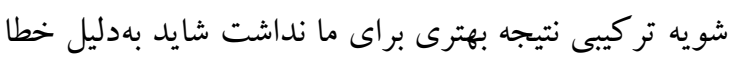

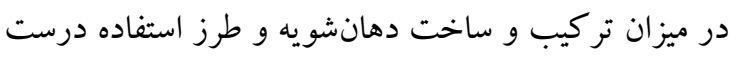
آن و شدت بنومونى در بيماران و تعداد كم نمونه هاى مورد

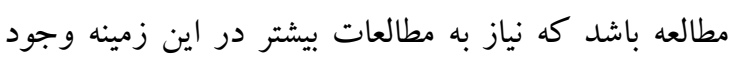

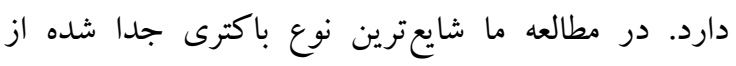

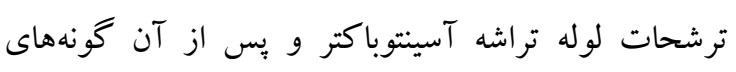
سودومونا، كلبسيلا و E.coli

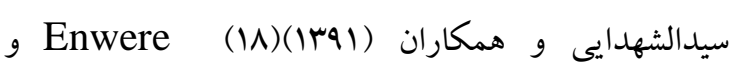

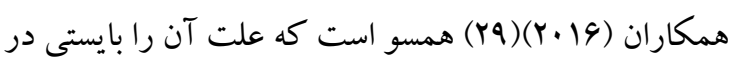
باكترى هاى مقاوم و بومى بخش مراقبت هاىويزٔه دانست كه

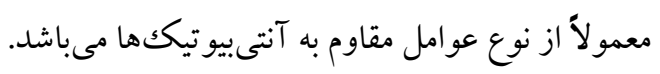

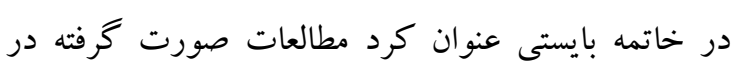

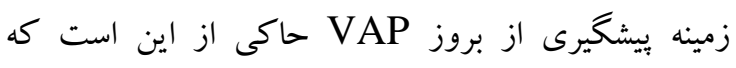

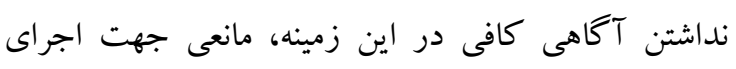

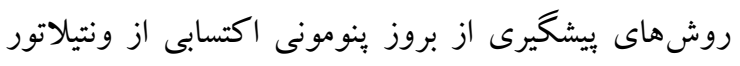

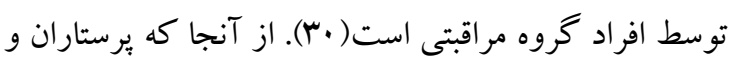

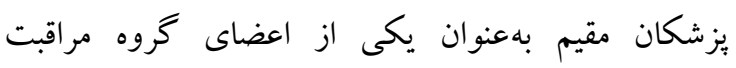
بهداشتى نقش منحصربهفردى در ييشخيرى و كنترل عفونت
از ونتيلاتور را كاهش داد، اما بر مورتاليته به هر علتى، طول مدت تهويه يا طول مدت بسترى در ICU در بيماران ونتيله

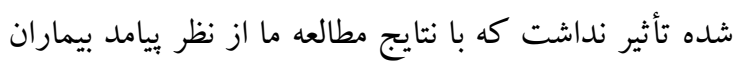

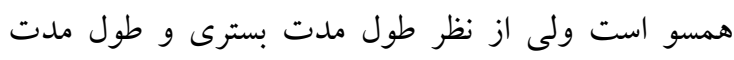

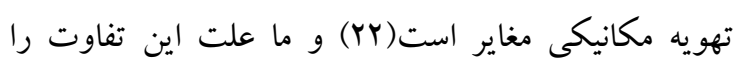

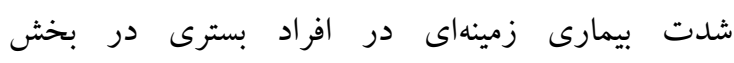

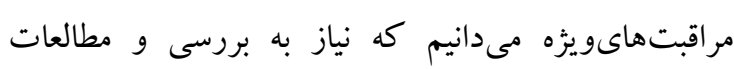
تكميلى در اين زمينه وجود دارد. و و همكاران (Neschepper كوهورت با حجم نمونه بسيار بالا به تأثير محلول دهانشويه

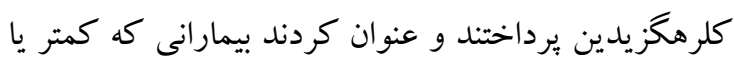

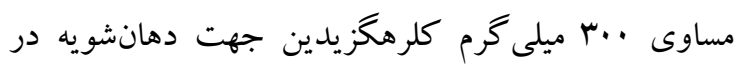
طى بسترى در بخش مراقبتهاىويزه دريافت كردهاند با كران

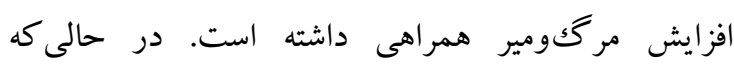

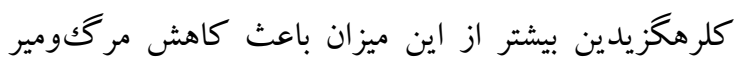

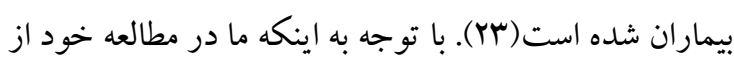

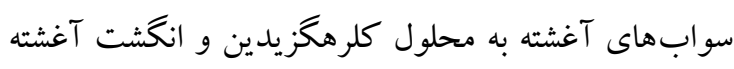
به دهانشويه تركيبى استفاده كرديم عملاً از ميزان دوز

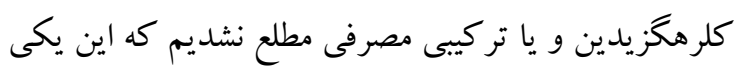

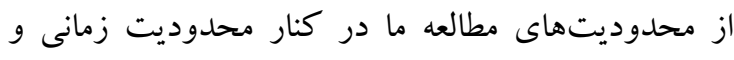

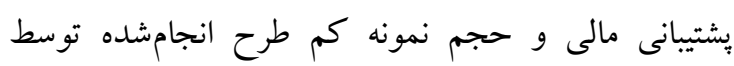

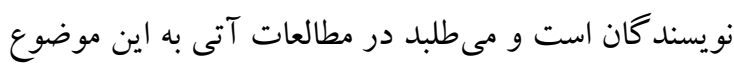

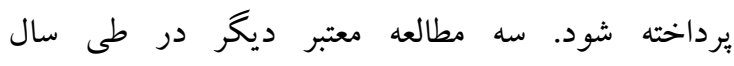

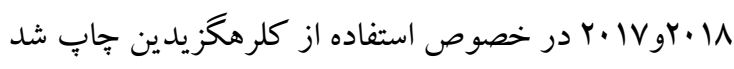
كه در اين بين Bouadma و همكارش (N) كردند كه به نظر آنها از محلول كلرهذزيد بندين نبايستى جهت بيشخيرى از بنومونى ناشى از ونتيلاتور استفاده كرد

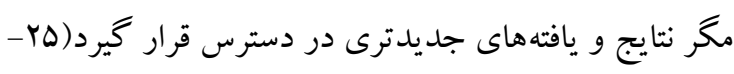

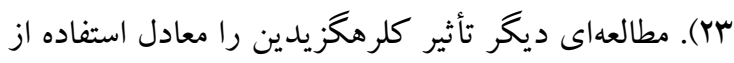

$$
\text { جايى سبز دانست(Y\&) }
$$

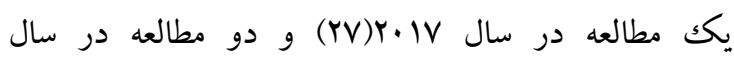

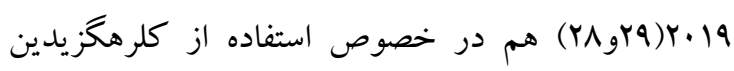

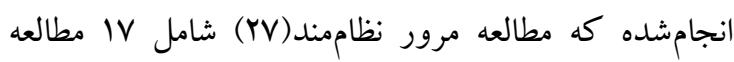




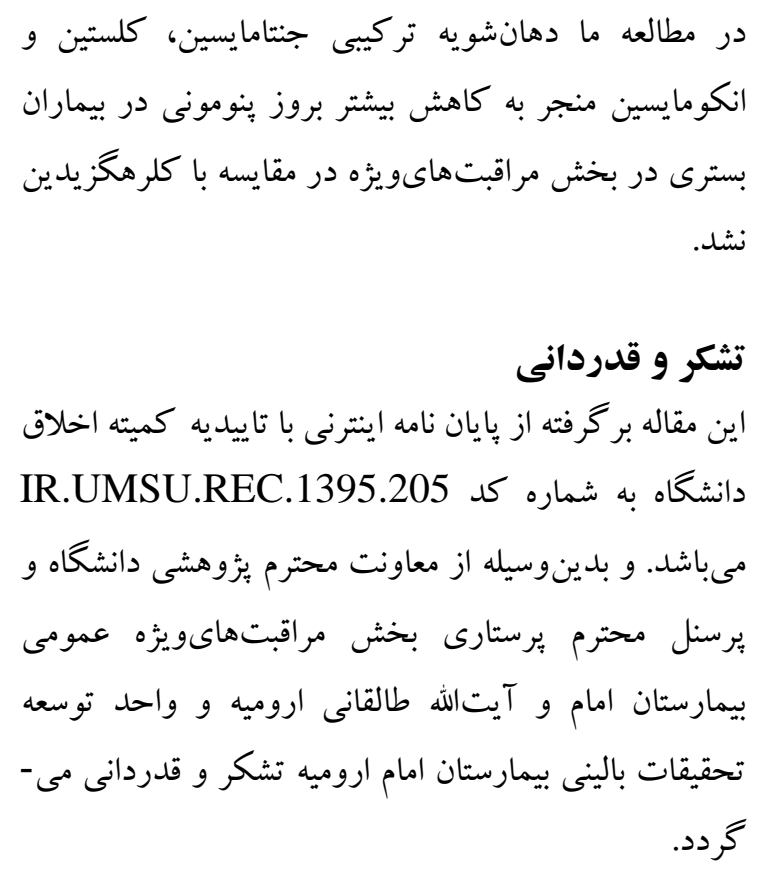

1. Afkhamzadeh ALF, Delpisheh A, Janmardi R. Incidence of ventilator - associated pneumonia and bacterial resistance pattern in adult patients hospitalized at the intensive care unit of Besat hospital in sanndaj. SJKV. 2011; 16(1):20-6.

2. Vincent JL, Abraham E, Moore FA, Kochanek PM, Fink MP Editors. Text book of critical care. 7th ed. Elsevier. 2017:477-92.

3. Labeau SO, Van de Vyver K, Brusselaers N, Vogelaers D. Prevention of ventilatorassociated pneumonia with oral antiseptics: a systematic review and meta-analysis. Lancet infect Dis. 2011; 11: 845-54.

4. Hutchins K, Karras G, Ewin J, Sulivan KL. Ventilator associated pneumonia and oral care: A successful quality improvement project. Am J Infect Control. 2009; 37(7): 590-7.

5. Khalifehzadeh A, Parizade A, Hosseini A, Yousefi H. The effects of an oral care practice on incidence of pneumonia among ventilator patients in ICUs of selected hospitals in Isfahan, 2010. Iran J Nurs Midwifery Res. 2012; 17(3): 216-9.

6. Munro CL, Grap MJ, Jones DJ, Mcclish DK, Sessler CN. Chlorhexidine, tooth brushing and preventing ventilator- associated pneumonia in critically ill adults. AM J crit care. 2009; 428-37.

7. Blot S, Vandijck D, And Labeau S. Oral Care Of Intubated Patients. Clin Pul Med. 2008; 15(3): 153-60.

8. Gholipour Baradari A, Darvishi Khezri H, Arabi S. Comparison of antibacterial effects of oral einses chlorhexidine and Matrien in patients admitted to intensive care unit. Bratisi med. 2010; 556-60.

9. Berry AM, Davidson PM, Masters J, Rolls K, Ollerton R. Effects of three approaches to standardized oral hygiene to reduce bacterial colonization and ventilator associated pneumonia in mechanically ventilated patients: a randomized control trial. Int Nurs Stud. 2011; 48(6): 681-8.

10. Marino Pl editor. Marino's the ICU book, 4th ed. Wolters kluwer. 2014: 77-96. 
11- Liao YM, Tsai JR, Chou FH. The effectiveness of an oral health care program for preventing ventilator-associated pneumonia.Nurs Crit Care. 2015 Mar; 20(2): 89-97.

12. Gallagher JA. Implementation of ventilator- associated pneumonia clinical guideline (Bundle). Nurse Pract. 2012; 41(1): 3777-82.

13. Svatka M, Nihada B, Natalie J, Matilda H, Stephen H, Hayley B. Reducing risk for ventilator associated pneumonia through nursing sensitive interventions. Intens crit care nurs. 2013; 15(2):261-66.

14. Bianca H, Christine W, Di Ch, Lindy K. Preventing ventilator- associated pneumonia through oral care, product selection, and application method: a literature review. AACN. 2013; 13(2):38-58.

15. Halm MA, Armola R. Effect of oral care on bacterial colonization and ventilatorassociated pneumonia. Am crit care. 2009; 18(3): 275-8.

16. Ranjbar H, Jafari S, Kamrani F, Alavi Majd H, Yaghmayee F, and Nasr Esfahani M. Effect of Chlorhexidine gluconate oral rinse on preventing of late onset ventilator associated pneumonia and it's interaction with severity of illness. crit care Nurs. 2010; 3(2): 81-86.

17. Browne JA, Evans D, Christmas LA, Rodriguez M. Pursuing excellence: development of an oral hygiene protocol for mechanically ventilated patients. Crit Care Nurs. 2011; 34(1): 2530.

18. Seyedalshohadaee M, Rafii F, Haghani H, Faridian Arani F. Evaluating the Effect of Mouth Washing with Chlorhexidine on the Ventilator Associated Pneumonia. Iran Journal of Nursing. 2012; 25(79): 34-44.

19. Johnstone L, Spence D, Koziol-McLain J. Oral hygiene care in the pediatric intensive care unit: practice recommendations. Pediatr Nurs. 2010; 36(2): 85-96.

20. Gholami Mehrabadi M, Khosravi Sh, Rezaie K, Malekianzadeh B, Ghorbanpour M, Moslemi A, et al. The effect of Echinacea mouthwash on ventilator associated pneumonia in patients in intensive care units. Medical-Surg Nurs. 2015; 4(3): 13-20.

21. Jabbari ghanatiM, Haghighi moghadam Y, Valizade Hasanloei MA,Ghraaghaji Asl R.Comparision of the effect of Two methods mouthwashe(Chiorhexidine and Chlorhexidine with Hydrogen peroxide solution) on ferequency of oral plaques in patients undergoing mechanical ventilation in the intensive care unit. Urmia Nurs Midwifery. 2018; 16(7)508-16.

22. Li J, Xie D, Li A, Yue J. Oral topical decontamination for preventing ventilator-associated pneumonia: a systematic review and meta-analysis of randomized controlled trials. Hosp Infect. 2013; 84(4): 283-293.

23. Deschepper M, Waegeman W, Eeckloo K, VogelaersD, Blot S. Effects of chlorhexidine gluconate oralcare on hospital mortality: a hospital-wide,observational cohort study. Intensive Care. 2018; 44:1017-26.

24. Bouadma L, Klompas M. Oral care with chlorhexidine: beware! Intensive Care.2018; 44:1153-155.

25. Zhang ZH, Hou Y, Zhang J, Wang B, Zhang J, Yang A,et al. Comparison of the effect of oral care withfour different antiseptics to preventventilator-associated pneumonia in adults:protocol for a network meta-analysis. Bio Med Central. 2017; 6:103.1-5.

26.Khanchemehr Y,Hoseynrezaei H,Kashani S,Khanchemehr A. Comparison of Green Tea and Chlorhexidine Mouthwash Effects on Bacterial Colonies of Throat Cultures of Patients in ICU. Infect Epid Microbiol. 2018; 4(2):59-65.

27. Gupta M, Garg R. Oral Hygiene Practices in Critically Ill Patient Requiring Endotracheal Intubation and Mechanical Ventilation. Anesth Crit Care. 2017; 7(1):1-5. 
28. Wei HP, Yang K. Effects of different oral care scrubs on ventilator associated pneumonia prevention for machinery ventilates patient. A protocol for systematic review, evidence mapping, and network meta-analysis. Medicine.2019; 98(12):1-5.

29. Enwere EN, Elofson KA, Forbes RC, Gerlach AT. Impact of chlorhexidine mouthwash prophylaxis on probable ventilator-associated pneumonia in a surgical intensive care unit. Inter Crit. Ill Inj. Sci. 2016; 6(1):1-8.

30. Mohammadi GhR, Ebrahimian AA, Mahmoudi H. Evaluating the knowledge of intensive care unit nursing staffs. Crit. Care. Nurs. 2009; 2 (1): 41-46. (Persian).

31. El-Khatib MF, Zeineldine S, Ayoub C, Husari A, Bou-Khalil PK. Critical care clinicians' knowledge of evidence-based guidelines for preventing ventilator-associated pneumonia. Am Crit. Care. 2010; 19 (3): 272-6. 